\title{
Investigation of resolution in lock-in thermography: theory and experiment
}

\author{
by D. $W u^{1}, C . Y . W u^{2}$, and G. Busse ${ }^{1}$
}

${ }^{1}$ Institut für Kunststoffprüfung und Kunststoffkunde, University Stuttgart, Pfaffenwaldring 32, D-70569 Stuttgart, Germany

${ }^{2}$ Department of Physics, University of Auckland, Auckland, New Zealand

\begin{abstract}
The general formalism of wave propagation and scattering effects is applied to optically generated thermal waves in order to describe imaging of near-surface features. The contrast functions of amplitude and phase calculated for flat bottom holes show good agreement with experimental results obtained with lockin-thermography.
\end{abstract}

\section{Introduction}

During the last decade thermal waves have found a lot of applications for nondestructive material evaluation (NDE). Lock-in thermography allowing for rapid inspection is relevant for industrial use [1-5]. Also the study of thermal wave propagation, diffraction, and scattering in materials is becoming a subject of interest for NDE [6-11].

For lock-in thermography one uses extented thermal wave sources (e.g. intensity modulated powerful lamps) thereby generating almost plane thermal waves in the sample. A steady state Green's function describing the material response to a periodic point source would be convenient for the analysis of contrast function of amplitude and phase image in the case of subsurface defects. An attractive point of using the steady state Green's function is that many concepts and techniques developed in wave motion studies (acoustics, electromagnetics) may be introduced into the thermal wave analysis [12-14].

In this paper the contrast function of phase and amplitude image is investigated. Some experimental results on model samples with flat top holes are compared with theoretical results.

\section{Thermal wave field}

The thermal field in materials satisfies the Eq. 1, and corresponding boundary conditions,

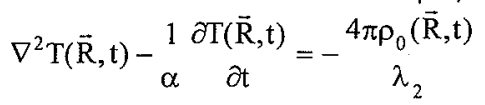

where $\alpha=\lambda / \rho \mathrm{c}$, with $\lambda, \rho$, and $\mathrm{c}$ being the heat conductivity $\left(\mathrm{W} \mathrm{m}^{-1} \mathrm{~K}^{-1}\right)$, density $\left(\mathrm{kg} / \mathrm{m}^{3}\right)$, and the specific heat $\left(\mathrm{J} \mathrm{kg}^{-1} \mathrm{~K}^{-1}\right)$ respectively, while $\rho_{0}(\vec{R}, \mathrm{t})$ describes the source distribution.

For a periodic source the thermal wave field $T(\vec{R}, t)$ can be written as $T(\vec{R}, t)=\Phi(\vec{R}) e^{i \omega t}$,

$$
\nabla^{2} \Phi(\vec{R})+\sigma^{2} \Phi(\vec{R})=-4 \pi \rho_{0}(\vec{R}) / \lambda_{2}
$$

where $\sigma=\frac{i \omega}{\alpha}$.

When the thermal wave source is on the surface of medium 2 (figure 1) $(\varepsilon=0$ ), we have

$$
\nabla^{2} \Phi(\overrightarrow{\mathrm{R}})+\sigma_{2}{ }^{2} \Phi(\overrightarrow{\mathrm{R}})=-\frac{4 \pi \mathrm{Q}_{0} \delta(\mathrm{z}+\varepsilon)}{\lambda_{2}} .
$$

The solution of Eq. 3 can be expressed as the integral, 


$$
\Phi(\overrightarrow{\mathrm{R}})=\mathrm{q}_{0} \int\left[\int_{-\mathrm{h}}^{0} \mathrm{G}\left(\overrightarrow{\mathrm{R}}, \overrightarrow{\mathrm{R}}_{0}\right) \delta\left(\mathrm{z}_{0}+\varepsilon\right) \mathrm{dz} \mathrm{z}_{0}\right] \mathrm{d} \overrightarrow{\mathrm{r}}_{0},
$$

where the Green's function satisfies

$$
\nabla^{2} \mathrm{G}\left(\overrightarrow{\mathrm{R}}, \overrightarrow{\mathrm{R}}_{0}\right)+\sigma_{2}{ }^{2} \mathrm{G}\left(\overrightarrow{\mathrm{R}}, \overrightarrow{\mathrm{R}}_{0}\right)=-4 \pi \delta\left(\overrightarrow{\mathrm{R}}-\overrightarrow{\mathrm{R}}_{0}\right) .
$$

Eq. 5 can be solved by performing Fourier transformations,

$$
\mathrm{G}\left(\overrightarrow{\mathrm{R}}, \overrightarrow{\mathrm{R}}_{0}\right)=\frac{1}{(2 \pi)^{2}} \iint \mathrm{g}\left(\mathrm{z}, \mathrm{z}_{0}\right) \mathrm{e}^{\mathrm{i} \vec{\xi}\left(\overrightarrow{\mathrm{r}}-\overrightarrow{\mathrm{r}}_{0}\right)} \mathrm{d} \vec{\xi}
$$

and

$$
\delta\left(\overrightarrow{\mathrm{r}}, \overrightarrow{\mathrm{r}}_{0}\right)=\frac{1}{(2 \pi)^{2}} \iint \mathrm{e}^{\mathrm{i} \vec{\xi}\left(\overrightarrow{\mathrm{r}}-\overrightarrow{\mathrm{r}}_{0}\right)} \mathrm{d} \vec{\xi}
$$

on both sides of Eq. 5 . This leads to an ordinary differential equation of the function $g\left(z, z_{0}\right)$. Under consideration of the boundary conditions, we obtain

$$
g\left(z, z_{0}\right)=\frac{4 \pi R_{23} e^{i \gamma_{2}(z+h)}+e^{-i \gamma_{2}(z+h)}}{i \gamma_{2}} \operatorname{R} R_{23} e^{i \gamma_{2} h}-e^{-i \gamma_{2} h} \cos \gamma_{2} z_{0} .
$$

Substituting Eq. 8 into Eq. 6 and Eq. 4 and setting the source depth $\varepsilon$ to zero we obtain the thermal wave field on the surface $(z=0)$

$$
\Phi(\vec{r}, 0)=\frac{4 \pi Q_{0}}{i \sigma_{2} \lambda_{2}} \frac{R_{23} e^{i \sigma_{2} h}+e^{i \sigma_{2} h}-e^{-i \sigma_{2} h}}{\text { i } h} .
$$

When small defects are located under the sample surface the total thermal wave field on the surface $\Phi(\vec{R})$ can be regarded as the linear superposition of the incident field $\Phi^{0}(\vec{R})$ and the scattered thermal wave fields of the defects $\Phi^{\mathrm{S}}(\overrightarrow{\mathrm{R}})(\mathrm{Eq} .10)$. It is here assumed that multiple and cross scattering can be ignored,

$$
\Phi(\vec{R})=\Phi^{0}(\vec{R})+\Phi^{\mathrm{S}}(\overrightarrow{\mathrm{R}})
$$

Performing the Green's theorem [11] on the whole surface $S_{f}+S_{a}+S_{c}$ (s. figure 1) the scattered thermal wave field can be expressed as an integration on the defect surface $S_{f}$,

$$
\Phi^{S}(\vec{R})=-\frac{1}{4 \pi} \int_{s_{f}} G\left(\vec{R}, \vec{R}_{0}\right) \frac{\partial \Phi^{0}\left(\vec{R}_{0}\right)}{\partial z} d s
$$

where the boundary conditions are $\frac{\partial \Phi^{\mathrm{S}}}{\partial z}=0$ at $z=0$ and $\frac{\partial \Phi^{\mathrm{s}}}{\partial z}=\frac{\partial \Phi^{0}}{\partial z}$ at the top of the hole $z=-h_{f}(s$. figure 1$)$.

For a thermally thick sample the scattered field of the single hole is

$$
\left.\Phi^{\mathrm{S}}(\overrightarrow{\mathrm{r}}, 0)=\mathrm{i} 4 \pi \mathrm{q}_{0} \mathrm{r}_{\mathrm{f}} \mathrm{e}^{\mathrm{i} \sigma_{2} \mathrm{~h}_{\mathrm{f}}} \int_{0}^{\infty} \frac{1}{\lambda_{2} \gamma_{2} \sin \left(\gamma_{2} \mathrm{~h}\right)}\left[\mathrm{J}_{0}\left(\xi \mid \overrightarrow{\mathrm{r}}-\overrightarrow{\mathrm{r}}_{\mathrm{f}}\right)\right]\right]_{1}\left(\xi \mathrm{r}_{\mathrm{f}}\right) \mathrm{d} \xi .
$$

For two defects the total field $\Phi(\vec{R})$ on the surface $(z=0)$ is the superposition of three terms,

$$
\Phi(\vec{R})=\Phi^{0}(\vec{R})+\Phi^{S_{1}}(\vec{R})+\Phi^{S_{2}}(\vec{R})
$$

Here $\Phi^{0}(\vec{R})$ is the incident thermal wave field, while $\Phi^{S_{1}}(\vec{R})$ and $\Phi^{S_{2}}(\vec{R})$ are the scattered fields induced by defect 1 and defect 2 , respectively. 


\section{http://dx.doi.org/10.21611/qirt.1996.044}

By using Eq. 12 and Eq. 13 the amplitude and the phase image of the thermal wave field on the surface can be calculated and compared with experiments. Figure 2 shows the geometry of a model which was investigated both in theory and experiment.

\section{Experiment}

Measurements of lock-in thermography were performed with an "AGEMA 900 lock-in" long wavelength IR-system. The synchronization of thermal wave excitation and IR-image acquisition was achieved by using a trigger box. The control signals for excitation sources (e.g. lamp) at various frequencies are calibrated in such a way that the temperature modulation on the sample surface has a sinusoidal form. The measurement setup is shown in figure 3.

The contrast on a model sample (PVC) having two flat top holes located in a depth of $1 \mathrm{~mm}$ underneath the surface (figure 2) was investigated. The distance between the two holes is $1 \mathrm{~mm}$ and their radius is $2 \mathrm{~mm}$. Line profiles of phase and amplitude measurements along the line through the centers of the two holes are shown in figure 4 . The four curves in each plot correspond to the frequencies $0.02,0.03,0.06$, and $0.12 \mathrm{~Hz}$ of the radiating thermal source. The comparable calculated values are shown in figure 5 . The diffusivity of PVC is about $0.0012 \mathrm{~cm}^{2} / \mathrm{s}$. For convenience of comparison, a constant of 0.13 , associated with the source strength and the system amplification, has been substracted from the amplitude contrast in figure 4 (right). For the same reason, a constant angle of $248^{\circ}$ has been added to each phase contrast in figure 4 (left).

Figure 6 shows the measured phase images (left) and simulations (right) at $0.03 \mathrm{~Hz}$ and $0.12 \mathrm{~Hz}$ respectively. As is shown, the agreement between theory and experiment is good. When the depth of the two holes is increased to $2 \mathrm{~mm}$, the resolution of the holes is becoming low. The measured and simulated phase image are displayed in figure 7 .

In figure 8 we show the line profiles of measured and calculated phase values on an aluminium sample which has the same geometry as in figure 2. Due to the low signal amplitude of the aluminum sample the phase signals are quite noisy.

\section{Summary}

In analogy to acoustics the amplitude and phase contrast functions of thermal waves have been calculated by using steady state Green's function. Both amplitude and phase images are dependent on frequency and thermal diffusivity of materials. Therefore the measurement can be optimized by selecting a certain frequency with maximum contrast and resolution. The comparison of theory and experiment shows a good agreement. The further effort of our work is to reconstruct size, depth, and kind of defects from the measurement data.

\section{Acknowledgement}

The authors are grateful to AGEMA Infrared Systems for generous support of research on lock-in thermography. This work was partially supported by German BMBF (03N8006BO).

\section{REFERENCES}

[1] BEAUDOIN (J. L.), MERIENNE (E.), DANJOUX (R.), and EGEE (M.). - Numerical system for infrared scanners by photothermal radiometry. Infrared Technology and Applications SPIE Proc. 590,1985 , p. 285-292

[2]KUO (P. K.), FENG (Z. J.), AHMED (T.), FAVRO (L. D.), THOMAS (R. L.), and HARTIKAINEN (J.)- Parallel thermal wave imaging using a vector lock-in video technique. 
Hess (P.) and Pelzl (J.) ed., Photoacoustic and Photothermal Phenomena. Heidelberg: Springer-Verlag, 1987, p. 415-418

[3] BUSSE (G.), WU (D.), and KARPEN (W.). - Thermal wave imaging with phase sensitive modulated thermography. J. Appl. Phys. 71, 1992, p. 3962-3965

[4]WU (D.) and BUSSE (G.). - Zerstörungsfreie phasenempfindliche Modulationsthermography, Prinzip und Anwendungen. Materialprüfung 36, 10, 1994, p. 393-399

[5]WU (D.), RANTALA (J.), KARPEN (W.), ZENZINGER (G.), SCHÖNBACH (B.), RIPPEL (W.), STEEGMÜLLER (R.), DIENER (L.), and BUSSE (G.). - Applications of lock-in thermography methods. Thompson (D. O.) ed., Review of Progress in Quantitative NDE, New York, Plenum Press, 1996, p. 511-519

[6] INGLEHART (L. J.), GRICE (K. R.), FAVRO (L. D.), KUO (P. K.), and THOMAS (R. L.). Spatial resolution of thermal wave microscopes. Appl. Phys. Lett. 43, 5, 1983, p. 446-448

[7]MANDELIS (A.). - Theory of photothermal-wave diffraction and interference in condensed media. J. Appl. Phys. 72, 8, 1992, p.3759-3764

[8]FRIEDRICH (K.), HAUPT (K.), SEIDEL (U.), and WALTHER (H. G.). - Definition, resolution and contrast in Photothermal imaging. J. Appl. Phys. 72, 8, 1992 p. 3759-3764

[9] CROWTHER (D. J.), FAVRO (L.D.), and KUO (P. K.). - Inverse scattering algorithm applied to infrared thermal wave images. Appl. Phys. 74, 9, 1993, p. 5828-5834

[10] LAU (S.K.), ALMOND (D. P.), and MLNE (J. M.). - A quantitative analysis of pulsed video thermography. NDT\&E Int. 24, 1991 p. 195-202

[11] VAVILOV (V. P.), KOURTENKOV (D. G.), GRINZATO (E.), BISON (P. G.), MARINETTI (S.), and BRESSAN (C.). - Inversion of experimental data and thermal tomography using "Termo.heat" and "Termidge" software. QIRT 94, Proc. Of the Eurotherm Seminar 42.1994 p. $273-278$

[12] KIBBLEWHITE (A. C.) and WU (C. Y.). - Wave interactions as a seismo-acoustic source. Lecture Notes in Earth Sciences, Springer-Verlag 1996

[13] MORSE (P. M.) and FESHBACH (H.). - Methods of theoretical physics. Chap. 7, McGrawHill Publishing Company, New York 1953

[14] FELSEN (L. B.) and MARUVITZ (N.) - Radiation and scattering of waves. Prentice-Hall Inc., 1973 


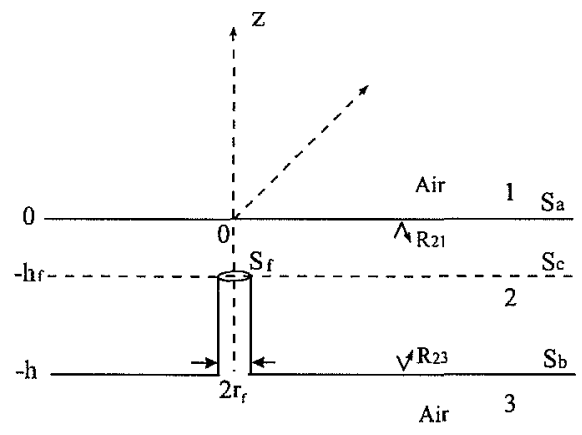

Fig. 1: The model of the material layer with inner flaw, illuminated from above by a photothermal source

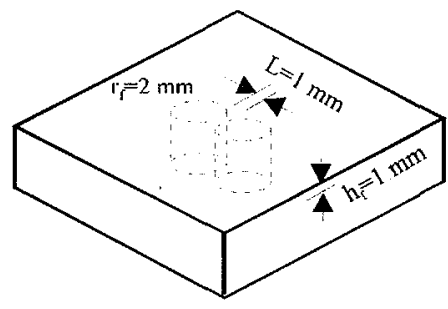

Fig. 3: A model sample (PVC) with two flat top holes, radius $r_{f}=2 \mathrm{~mm}$, distance $L=1 \mathrm{~mm}$, and depth $h_{f}=1 \mathrm{~mm}$

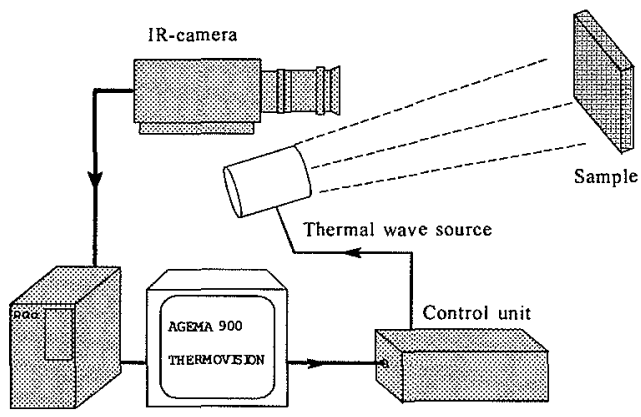

Fig. 2: Setup for lock-in thermography
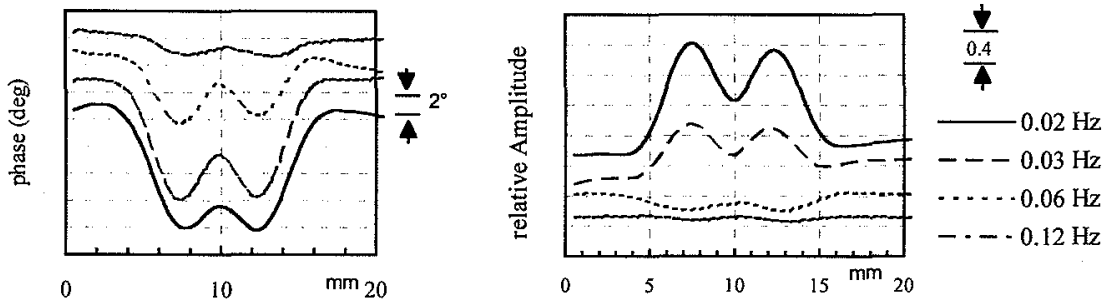

Fig. 4: Phase (left) and amplitude (right) curves of measurements at various frequencies
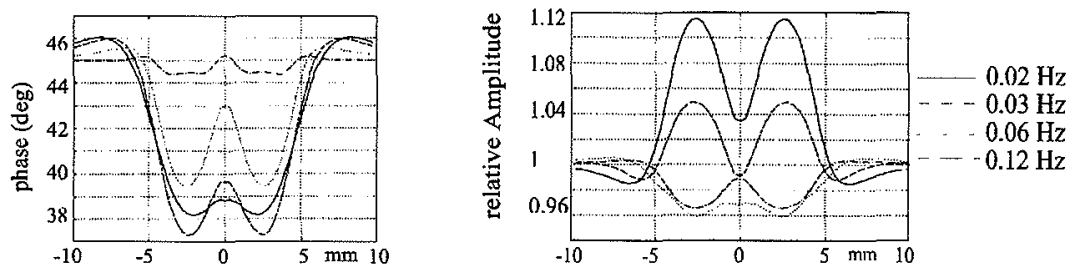

Fig. 5: Calculated phase (left) and amplitude (right) plots at various frequencies 


\section{http://dx.doi.org/10.21611/qirt.1996.044}
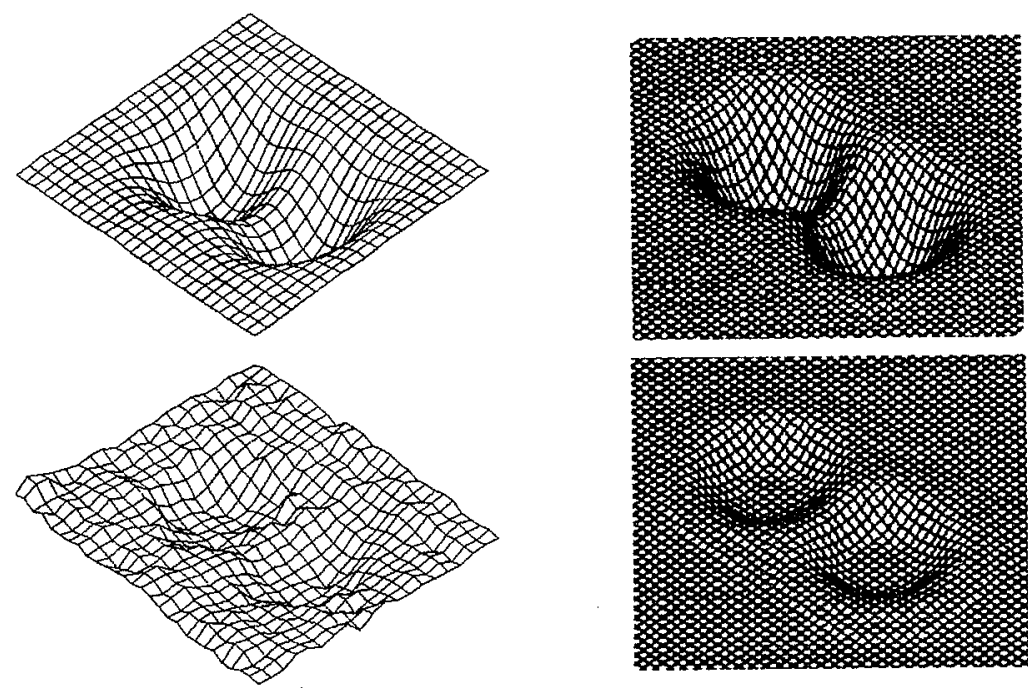

Fig. 6: Measured phase images (left) and simulations (right) at $0.03 \mathrm{~Hz}$ (top) and $0.12 \mathrm{~Hz}$ (bottom)
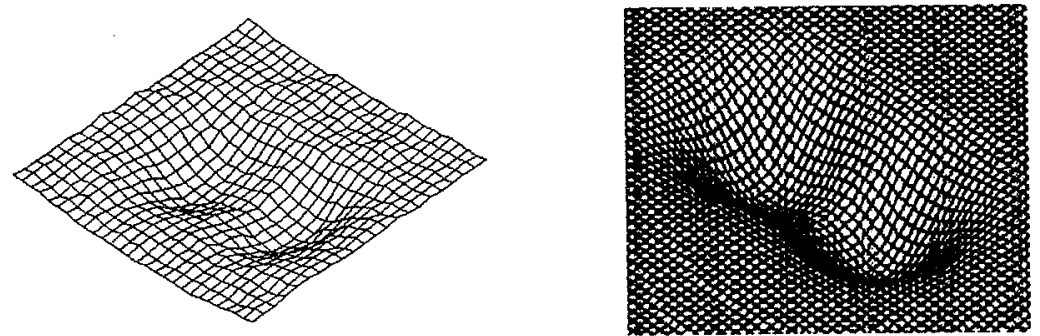

Fig. 7: Measured (left) and simulated (right) results on a PVC-sample with two holes in the depth of $2 \mathrm{~mm}$
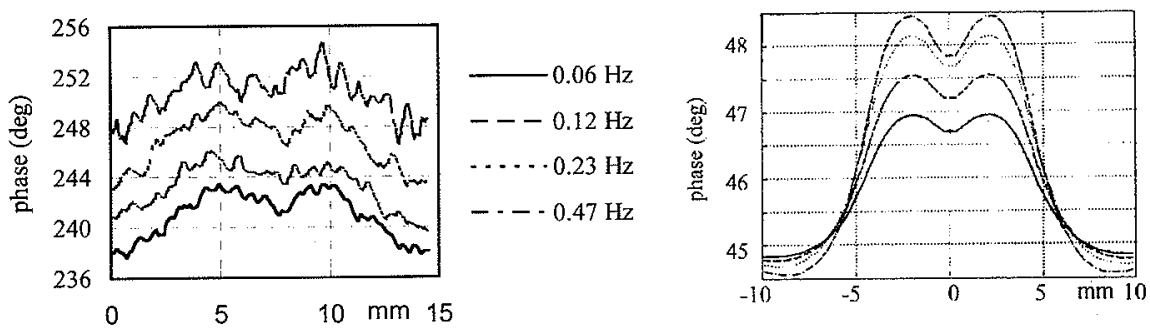

Fig. 8: Measurements and calculations on an Al-sample with the same geometry as in fig. 3 